\title{
Awareness and Expectations Surrounding Family Planning and Pregnancy Among Danish Patients with Chronic Inflammatory Disease of the Skin or Joints: Results from an Online Survey
}

\author{
Cæcilie B. Johansen (D) · Trine B. Laurberg (D) · Alexander Egeberg • \\ Ulla-Fie A. Jensen · Asbjørn L. Hansen · Lone Skov (D) • \\ Lars E. Kristensen · Simon F. Thomsen (D) - Karen Schreiber
}

Received: April 28, 2021 / Accepted: July 6, 2021 / Published online: August 14, 2021

(C) The Author(s) 2021

\section{ABSTRACT}

Background: Patients with chronic inflammatory diseases (CIDs) may encounter challenges in their family planning journey. Here, we report on the access to family planning and

Supplementary Information The online version contains supplementary material available at https:// doi.org/10.1007/s40744-021-00348-2.

C. B. Johansen $(\bowtie) \cdot$ A. Egeberg · S. F. Thomsen Department of Dermatology and Venereology, Copenhagen University Hospital Bispebjerg and Frederiksberg, Bispebjerg Bakke 23, 2400

Copenhagen, Denmark

e-mail: cillebachdal@gmail.com

T. B. Laurberg

Department of Rheumatology, Aarhus University

Hospital, Aarhus, Denmark

U.-F. A. Jensen · A. L. Hansen

UCB Pharma, Copenhagen, Denmark

L. Skov

Department of Dermatology and Allergy, Herlev and Gentofte Hospital, University of Copenhagen, Copenhagen, Denmark

L. E. Kristensen

The Parker Institute, Copenhagen University

Hospital Bispebjerg and Frederiksberg,

Frederiksberg, Denmark

K. Schreiber

Danish Hospital for Rheumatic Diseases,

Sonderburg, Denmark pregnancy (FPP) information and the concerns among patients in Denmark with CIDs.

Methods: Patients aged 18-50 years with CIDs participated in an online survey. Patients were recruited through patient advocacy groups and were asked to report information on their diagnosis, concerns related to FPP and perceptions of access to FPP information. Descriptive statistics were applied.

Results: Of the eligible respondents, 368 had rheumatological diagnoses (rheumatoid arthritis, psoriatic arthritis, juvenile idiopathic arthritis or axial spondyloarthritis; mean age 40 years; $83 \%$ women, $17 \%$ men) and 95 had dermatological diagnoses (psoriasis or psoriatic arthritis; mean age 38 years; $67 \%$ women, 33\% men). Approximately $70 \%$ of all patients reported seeking FPP information from patient advocacy groups; $57 \%$ of both cohorts used the internet as information sources; and $73 \%$ and $42 \%$ of rheumatological and dermatological cohorts used their hospital and specialist doctor, respectively. Despite this, $58 \%$ and $67 \%$ of patients with rheumatological and dermatological diagnoses reported limited or no access to FPP information, with $>70 \%$ of dermatological patients of early/mid-reproductive age reporting a lack of access to this information. Overall, $68 \%$ of patients with rheumatological and $73 \%$ with dermatological diagnoses had biological children, amongst whom $24 \%$ and $18 \%$, respectively, indicated their disease affected the number of children they ultimately 
decided to have. The most frequent FPP concerns among patients who did not want any/more biological children were disease worsening, heredity and taking care of the child.

Conclusions: Despite awareness of available sources of FPP information, patients expressed experiencing a feeling of limited access to information and having concerns that affect key decisions regarding FPP. The results of this survey highlight a need for improved and more standardised FPP information for patients with CIDs in Denmark.

Keywords: Pregnancy; Family planning; Chronic inflammatory disease; Online survey

\section{Key Summary Points}

Patients with chronic inflammatory diseases may encounter challenges in their family planning journey.

This survey assessed the awareness of, and access to, family planning and pregnancy information among Danish patients with chronic inflammatory diseases.

Respondents reported limited access to information, as well as concerns which affect their family planning journey.

The results of this survey provide insight on an unmet need in Denmark and the areas where healthcare providers may need to provide more standardised and accessible information.

\section{INTRODUCTION}

Chronic inflammatory diseases (CIDs) of the skin or joints, such as axial spondyloarthritis (axSpA; including non-radiographic [nr-] axSpA and ankylosing spondylitis [AS]), juvenile idiopathic arthritis (JIA), psoriatic arthritis (PsA), psoriasis (PsO) and rheumatoid arthritis (RA), can impact patients' attempts to start a family.
CIDs have been associated with adverse pregnancy outcomes, such as preterm birth, intrauterine growth restriction and low birth weight $[1,2]$. In addition, evidence suggests that patients with CID may experience a lower likelihood of pregnancy and a lower rate of live births compared to their healthy counterparts and that disease activity, comorbidities and medication use may impact the likelihood of women becoming pregnant [3-9].

Reports on the level of disease activity during pregnancy are mixed in patients with rheumatological and dermatological diseases [10-13]. Whilst some patients have reported stabilisation or improvements in symptoms during pregnancy [12], others have reported an exacerbation of disease activity, highlighting the variation in experiences at the patient level [14-16]. The concern of foetal or infant exposure to medication, justified or not, is deeply embedded among patients and physicians $[9,17,18]$.

The clinical dilemma between the need for continuous treatment of these chronic diseases and the patient's wish to conceive calls for careful consideration, professional counselling and planning to enable patients to make informed decisions [18]. Currently, a number of guidelines provide recommendations for patients with rheumatological diseases who are of reproductive age [19-22]. Similar formal clinical guidelines for the treatment of patients with dermatological diagnoses, whilst available, are less prevalent $[11,23]$.

Real-world data collected from patient advocacy groups may help to inform the local implementation of available recommendations and the awareness of these among healthcare providers. The results of a multinational survey of 969 patients treated by rheumatologists and gastroenterologists in Europe and the USA showed that most patients' concerns regarding family planning and pregnancy (FPP) were inadequately or inconsistently addressed [24]. Similar findings have also been shown in patients diagnosed with PsO (including PsA) [25].

The objective of this study was to investigate the level of FPP information received by and the potential FPP concerns among Danish patients with CIDs. 


\section{METHODS}

\section{Survey Distribution and Patient Eligibility}

An online survey was conducted from 19 September to 15 October 2019 by an independent third-party vendor (Incentive Denmark, Holte, Denmark). Patients were recruited from Danish patient advocacy groups (The Arthritis Association, The Association for Spinal Arthritis and Bechterew's Disease, and The Psoriasis Association) who provided their members with a link to the survey on their websites and emails.

Patients aged 18-50 years with a self-reported diagnosis of CID were eligible for participation. Patients not meeting the age criteria and those who did not indicate their gender or disease were excluded. Patients who only partially completed the survey or did not agree to participate were also ineligible for inclusion in the analysis.

As the survey requested rheumatology- and dermatology-specific responses for some questions, links for two different versions of the survey were sent to the rheumatology versus the dermatology patient advocacy groups. PsA was represented as a diagnosis in both the rheumatological group and dermatological group in order to avoid patients' self-exclusion. These patients were therefore allocated to a cohort based on the advocacy group through which they accessed the link.

Patients completed the survey voluntarily and did not receive payment for participation.

\section{Survey Design}

The survey was designed in collaboration with specialists in dermatology and rheumatology and consisted of 34 closed-ended questions. Respondents were informed that the survey would take 10-15 min to complete and were provided with a statement explaining that the appropriate ethical guidelines had been followed, the answers were anonymous and the data were to be handled and organised according to Danish legislation and the General Data Protection Regulation (EU) 2016/679 (GDPR).
Patients were required to actively indicate that they agreed to these terms and conditions and could withdraw from the survey at any time. Ethics approval was not required for this study as questionnaire surveys not involving human biological material are exempt from the obligation to notify the scientific ethics committee (Sect. 14 (2) of the Committee Act).

The survey included questions regarding:

- Patient demographics and disease characteristics;

- Level of patient knowledge and feelings of access to FPP information;

- Sources of information about disease course and treatment in relation to pregnancy;

- Patients' family planning concerns;

- In women who had biological children, their disease status during and after previous pregnancies;

- Treatment(s) taken for managing the patient's disease.

As the survey was closed-ended, except for providing a numeric response for their age, patients could only provide answers that were selected from a distinct set of pre-defined responses. The full survey and possible answers are shown in Electronic Supplementary Material Table S1.

\section{Statistical Analysis}

The sampling strategy was aimed at receiving responses from 1000 patients aged 18-50 years. Descriptive statistics were applied. Data are reported as proportions of patients answering each question. Questions not applicable to patients were not provided for their completion (e.g. questions on pregnancy experience were not presented to male respondents). For some questions respondents could select "do not know", which led to variable denominators being applied. 


\section{RESULTS}

\section{Patient Characteristics}

\section{Demographics}

A total of 976 patients with rheumatological diagnoses and 136 patients with dermatological diagnoses responded to the survey. Of these patients, 368 with rheumatological diagnoses and 95 with dermatological diagnoses met the eligibility criteria and completed the survey. Approximately $83 \%$ of rheumatological respondents and $67 \%$ of dermatological respondents were women, and the mean (standard deviation [SD]) age of the rheumatological and dermatological groups overall was 40.0 (7.4) years and 38.3 (8.2) years, respectively. Mean (SD) age at diagnosis and patient characteristics and demographics are shown in Table 1.

\section{Prior Experience with Starting a Family}

A slightly higher proportion of men reported having biological children compared with women: in the group with rheumatological diagnoses, $80 \%$ of men $(51 / 64)$ versus $65 \%$ of women (198/304); in those with dermatological diagnoses, $81 \%(25 / 31)$ of men versus $69 \%$ (44/ $64)$ of women. The mean (SD) number of children patients had relative to their diagnosis was 1.4 (1.1) children prior to, and $0.6(0.9)$ children after, diagnosis for those with rheumatological diagnoses, whilst for those with the dermatological diagnoses, an inverse trend was observed, as this was reported to be $0.3(0.7)$ and 1.8 (1.0) children, respectively (ESM Table S2).

\section{Prior Experience with Disease Activity Changes During/After Recent Pregnancy (Women)}

Overall, $16 \%(32 / 198)$ of women with rheumatological diagnoses reported disease worsening during their most recent pregnancy; this proportion was greatest amongst women with 'several types of arthritis' (33\%; 5/15) and axSpA only $(29 \% ; 15 / 51)$. Disease improvement during pregnancy was reported by $31 \%(61 / 198)$ of women overall. In contrast, $34 \%(67 / 198)$ reported disease worsening post-partum, and
6\% (12/198) reported improvement (ESM

Fig. S1a).

In women with dermatological diagnoses, disease worsening during pregnancy was reported by $20 \%(9 / 44)$, while twice this proportion (41\%; 18/44) reported experiencing disease improvement. After pregnancy, 59\% (26/44) of women reported experiencing disease worsening versus just $2 \%(1 / 44)$ who reported improvement. Overall, disease change was more pronounced in the PsO cohort both during and after pregnancy compared with the combined $\mathrm{PsO}$ and PsA cohort (ESM Fig. S1b).

\section{Access to FPP Information}

When asked "To what extent do you feel that you have had access to pregnancy and family planning information?", of all patients $(N=463), 60 \%$ reported that their access was "to a lesser degree" or "not at all". This lack of access was reported by 58\% (214/368) and 67\% $(64 / 95)$ of patients with rheumatological and dermatological diagnoses, respectively. When stratified by gender, reports of a lesser degree or complete lack of access were greatest in women with dermatological disease, with significantly more women $(45 \%$; 29/64) reporting their access as "not at all" compared with men (29\%; $9 / 31$ ). When stratified by age, lack of access to information was reported the most by those in the early- and mid-reproductive age groups for all patients (male and female) with dermatological disease $(73 \% ; n=41)$ and by those in the mid- and late-reproductive age groups for patients with rheumatological disease (59\%; $n=329$ ) (Fig. 1a, b).

Across diagnoses, more women than men reported seeking information from family and friends, social media and the internet relative to other information sources. In the rheumatological cohort, $13 \%(39 / 304)$ of women versus $5 \%(3 / 64)$ of men reported consulting their family and friends, $35 \%(105 / 304)$ versus $20 \%$ $(13 / 64)$ opted for social media and 58\% (177/ $304)$ versus $48 \%(31 / 64)$ sought information from the internet. In the dermatological cohort, $17 \%(11 / 64)$ of women versus $3 \%(1 / 31)$ of men reported using their family and friends as 


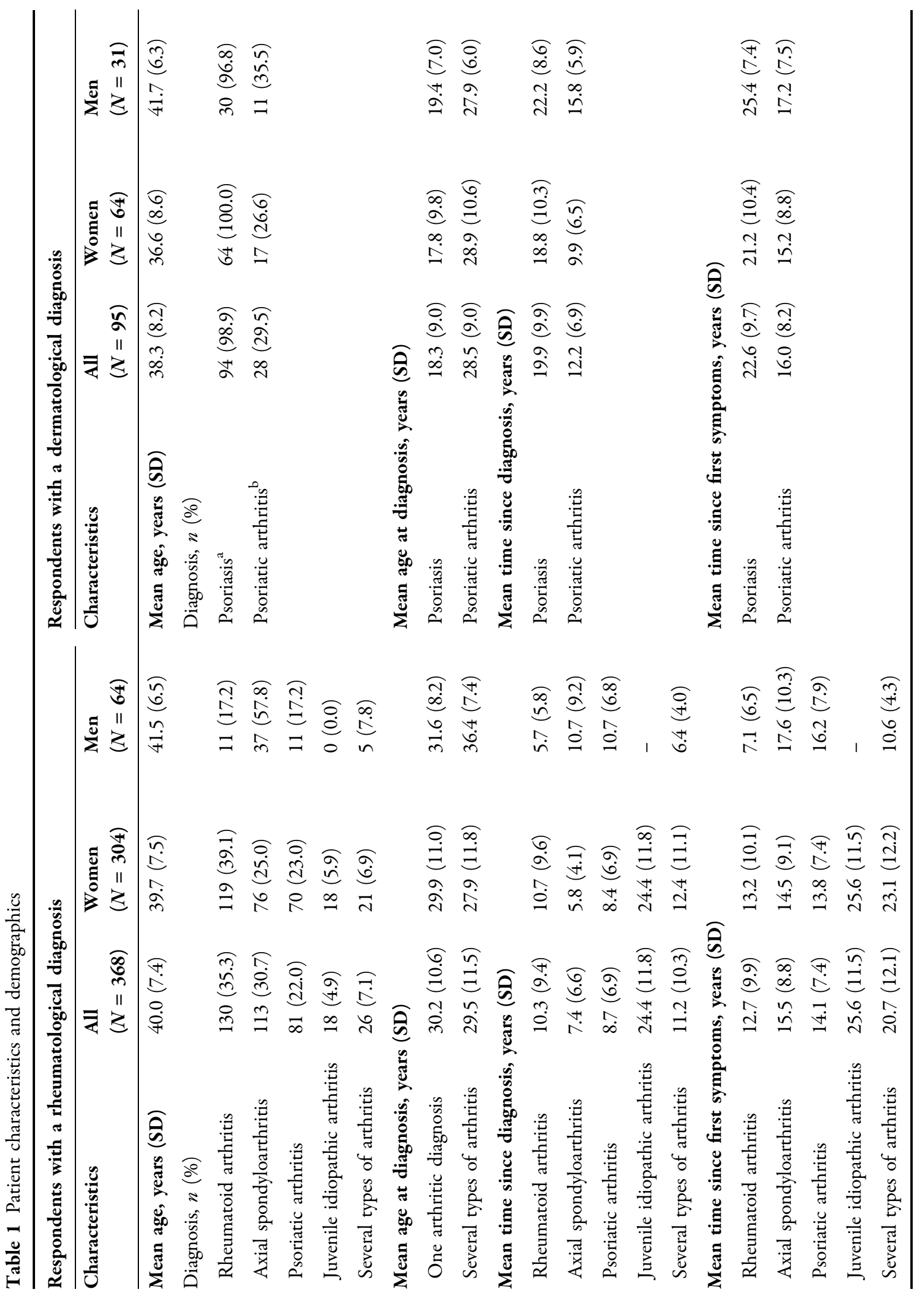




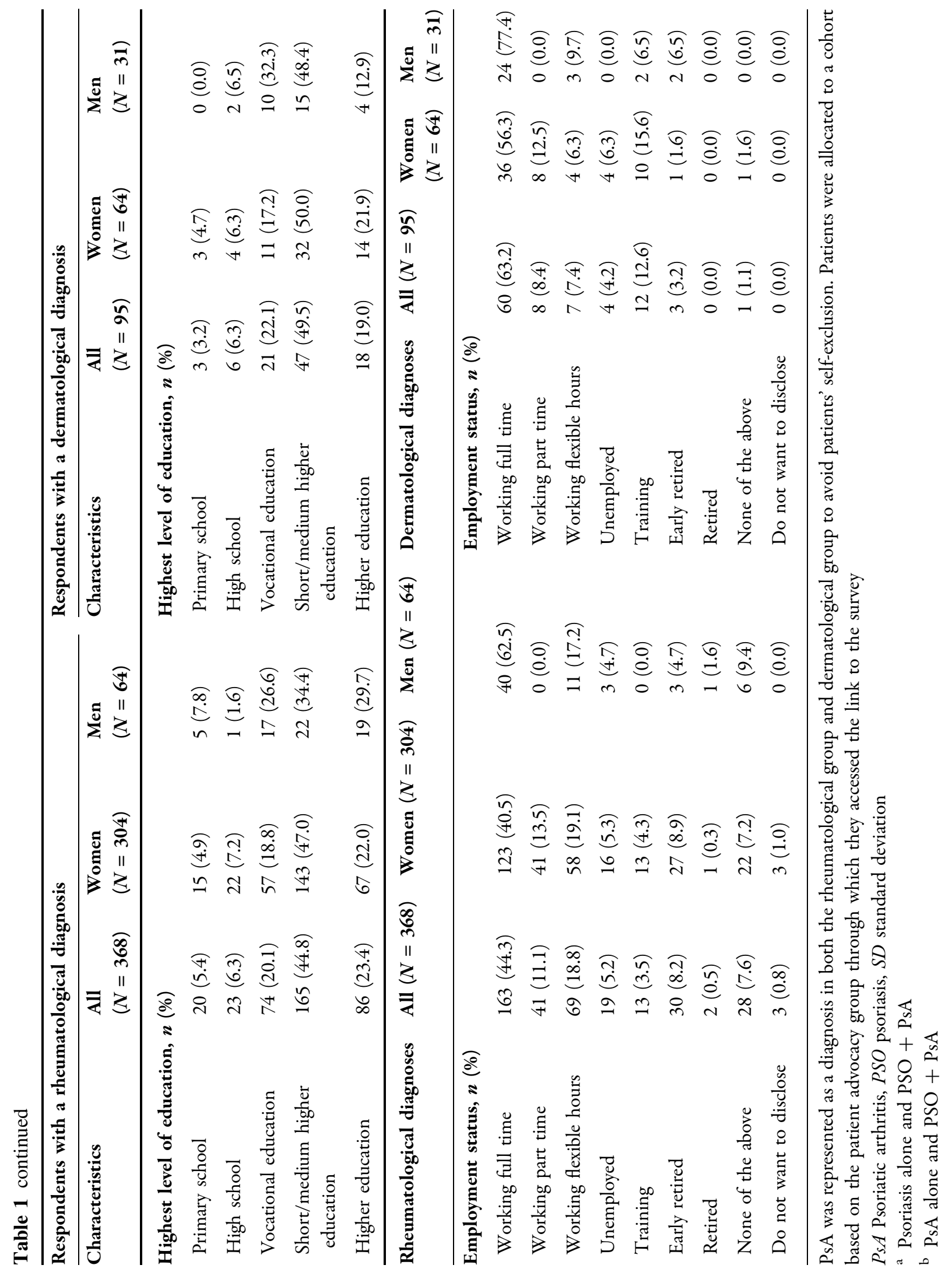



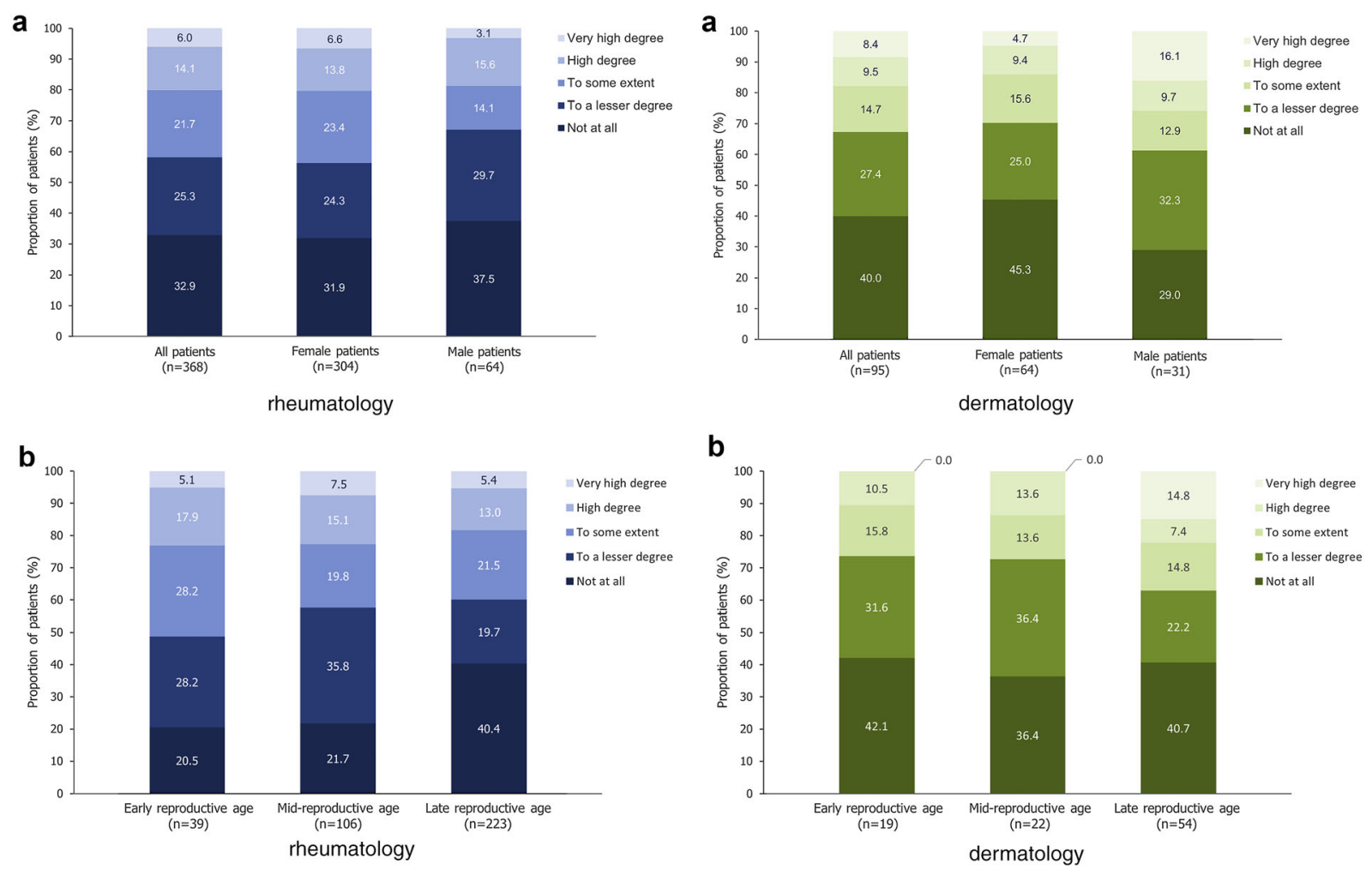

Fig.1 Access to family planning and pregnancy information. "To what extent do you feel that you have had access to pregnancy and family planning information?" a Proportions of patients reporting levels of access to pregnancy and family planning information-overall and by gender (rheumatological patients, dermatological patients).

information source, 30\% (19/64) versus 13\% (4/ 31 ) opted for social media and $64 \%(41 / 64)$ versus $42 \%(13 / 31)$ reported using the internet. However, in the dermatological cohort a greater proportion of men $(42 \%$; 13/31) compared with women $(25 \%$; $16 / 64)$ also commonly sought information from their hospital doctor. Overall, the most used sources of information on disease and treatment among patients with rheumatological diagnoses were patient advocacy groups (74\%; 274/368), their hospital doctor (73\%; $267 / 368)$ and the internet $(57 \% ; 208 / 368)$. Amongst patients with dermatological diagnoses the most used sources were patient advocacy groups $(69 \%$; 66/95), the internet $(57 \% ; 54 / 95)$ and their doctor in specialist practice (42\%; 40/95) (Fig. 2).

b Proportions of patients reporting levels of access to pregnancy and family planning information-by reproductive age group (rheumatological patients, dermatological patients) (early reproductive age [18-29 years]; midreproductive age [30-39 years]; late reproductive age [ $40-50$ years $]$

\section{Family Planning and Pregnancy Concerns}

\section{Past and Current Family Planning and Pregnancy}

Across diagnoses, both genders indicated to a similar level that their disease affected their ability to become a parent; for those with rheumatological diagnoses this was 23\% (84/ 368 ) overall (women 23\% [71/304]; men 20\% [13/64]), and for those with dermatological diagnoses this was $8 \%(8 / 95)$ overall (women $8 \%$ [5/64]; men 10\% [3/31]).

When women were asked whether they had concerns before or during their most recent pregnancy due to their medical treatment, large proportions in both patient populations reported that they did not, with approximately 75\% $(n=203)$ of women with rheumatological 
disease and $80 \%(n=44)$ of women with dermatological disease reporting that they were not worried.

\section{Future Family Planning and Pregnancy}

When asked whether their illness has affected how many biological children they have chosen to have, $24 \%(89 / 368)$ of rheumatological patients agreed that they have chosen to have fewer or more children (women 25\% [75/304]; men $22 \%$ [14/64]). Similar but reduced proportions of dermatological patients reported making the same decision (18\% [17/95]; women 19\% [12/64]; men: 16\% [5/31]).

In rheumatological patients, $67 \%(248 / 368)$ did not want biological children or did not want to have more biological children than they already had (women 67\% [203/304]; men 70\% [45/64]). For those without biological children who did not plan on having them $(n=51), 33 \%$ (women 36\% [16/44]; men 14\% [1/7]) stated that they had never wanted to have children, and $34 \%(15 / 44)$ of women cited the potential physical impact of a pregnancy. A high
Fig. 3 The most frequent family planning and pregnancy concerns. a Rheumatological patients with no biological children-"What is the reason you do not want biological children?” b Rheumatological patients with biological children- "What is the reason you do not want more biological children?" c Dermatological patients with biological children- "What is the reason you do not want more biological children?”

proportion also gave reasons related to their disease for not wanting children, including worries of not being able to take care of the child due to their disease burden (39\%; women $39 \%$ [17/44]; men 43\% [3/7]), heredity (inheritance of the disease by the child: $35 \%$; women $32 \%$ [14/44]; men 57\% [4/7]) and concerns that their disease will get worse (31\%; women $27 \%$ [12/44]; men 57\% [4/7]) (Fig. 3a). These concerns were raised to a lesser extent by patients who already had biological children but did not plan to have more, as the majority (72\%; 142/197) stated they already had the children they wanted to have (Fig. 3b).

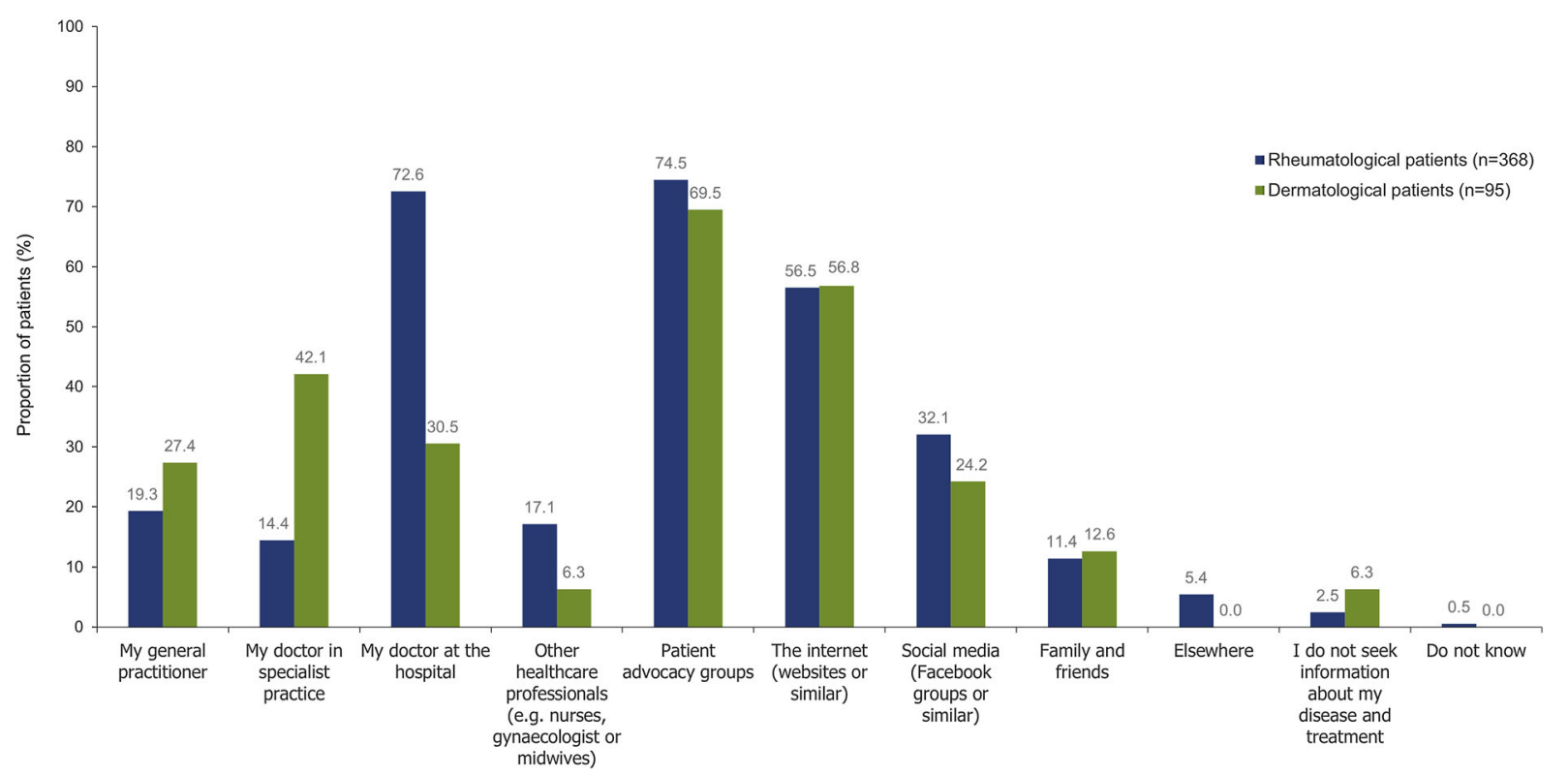

Fig. 2 Sources of information on disease and treatment. "Where do you generally find information about your illness and treatment? (you may tick off more than one)”. The options for patient advocacy groups included The Arthritis Association (Gigtforeningen), The Association

for Spinal Arthritis and Bechterew's Disease (Foreningen for Rygsøjlegigt og Morbus Bechterew), The Psoriasis Association (Psoriasisforeningen), and 'other' patient associations 

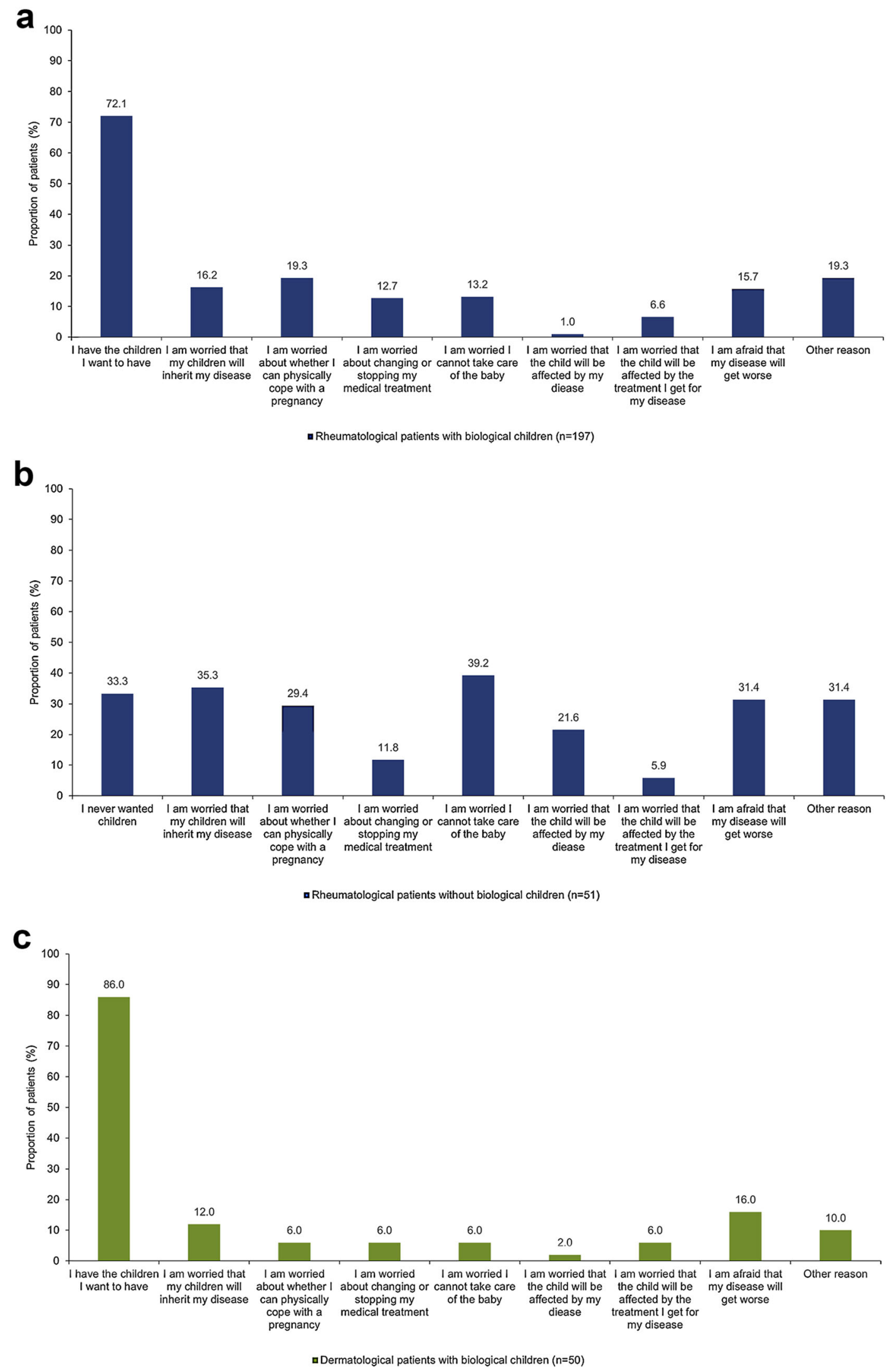
In dermatological patients, low numbers of patients did not have biological children and did not plan on having them $(n=6)$; therefore limited conclusions can be drawn regarding FPP concerns in this subpopulation. Among dermatological patients with biological children who did not want more $(n=50)$, fears that their disease would get worse (16\%; women $21 \%$ [7/ $33]$; men $6 \%$ [1/17]) and heredity (12\%; women $3 \%$ [1/33]; men $29 \%$ [5/17]) were the most frequent FPP concerns (Fig. 3c).

\section{DISCUSSION}

This survey found that Danish patients of reproductive age with a CID-especially those with dermatological diagnoses in the early- and mid-reproductive age groups-have concerns which can impact their FPP decisions. Patients also reported a feeling of limited access to FPP information, pointing out an unmet information need, particularly from healthcare providers. This expands upon the knowledge of previous studies $[26,27]$.

Stratified by reproductive age, the rheumatological and dermatological patients showed a nearly inverse relationship between reproductive age and reported access to FPP information. This might be reflective of an increasing focus on FPP in the Danish rheumatological guidelines in recent years-and the lack thereof in the Danish dermatological guidelines [28, 29].

In the dermatological cohort the lack of access to FPP information was largest among those in the early- and mid-reproductive age groups, i.e. the age groups with the most people about to start a family. This result is highly indicative of the need for structured dermatological FPP guidelines. Inadequate provision of FPP information to this group has previously been reported by Lebwohl et al., wherein $>75 \%$ of the patients with PsA and PsO had to initiate discussions around family planning with their healthcare provider themselves [30]. This finding was supported by the National Psoriasis Foundation survey in which only $7 \%$ of patients stated that their healthcare provider initiated the family planning conversation [25].
Patients reported concerns related to their CID that had impacted family planning decisions, such as their decision to have biological children. We found that rheumatological patients often had their children prior to their diagnosis, which contrasts with the patients with dermatological diagnoses who often had children after their diagnosis. This may reflect an earlier onset of dermatological disease in these patients or the possibility that they do not experience the same diagnostic challenges as patients with rheumatological diagnoses [31]. Patients with dermatological diseases may also be more likely to have diagnoses earlier on in their reproductive years due to the detection of associated immune-mediated inflammatory diseases prior to their diagnosis [32].

The lack of concern about pregnancy due to medical treatment reported in a large proportion of female patients in the rheumatological cohort may be due to more of these women having had their children prior to diagnosis and treatment, or to a feeling of more reassurance with disease management within the hospital setting. Overall, the reasons for this should be explored further. For those with dermatological diagnoses, this lack of concern could reflect less severe disease, or to the influence of factors such as familial experience and a difficulty in obtaining a referral to a specialist, which may discourage health-seeking behaviours-albeit this may differ across various healthcare systems [33].

Patients reported extensive use of patient advocacy groups as sources of information, although this use is reflective of the way the patients were recruited and may differ significantly from the general population. Hospital doctors were commonly consulted and, to a greater extent for dermatological patients, their general practitioner and doctor in specialist practice. Considering the seemingly available contact with key healthcare professionals, barriers may still exist here to cause the patients in this survey to report a lack of access to FPP information. Examples of these barriers could include a lack of evidence-based resources for physicians to guide reproductive decision-making, competing priorities during clinic visits and physician unawareness of FPP as being a part of 
their clinical responsibilities [34-36]. Across diagnoses, the internet and social media were commonly reported as sources of information. However, it must be noted that online sources of information may be inadequate to address patients' educational needs as these sources may be outdated and/or provide misinformation or the information may not cover all essential topics related to their disease and FPP [37]. With patients increasingly embracing technology to access information, and their treating physicians perhaps being unaware of this, it is important that all physicians (in primary and secondary care) are aware of the available content patients may access in order to guide them appropriately [38].

In this survey, women across diagnoses reported stabilisation, worsening and improvements in disease during pregnancy. The results described here reflect that some CIDs (RA, PsA, JIA, and PsO) remain stable or tend to improve during pregnancy, in contrast to axSpA which is often aggravated during pregnancy [10-16, 39]. However, these data are self-reported by patients, so it must be noted that a symptom associated with pregnancy, such as mechanical back pain, could have been perceived as disease worsening, potentially confounding findings in the axSpA population. Post-partum flares were reported by both groups of patients and were more prominent amongst women with PsO, also confirming previous findings [10-12, 15]. However, this must be interpreted with caution, as this survey was not designed to account for whether the reported flares were in fact a return to the patients' baseline psoriatic body surface area, a phenomenon observed by Murase et al.[12]

There are several limitations to this study. As enrolment was conducted through online links on the websites of patient advocacy groups, patients who were not members of an advocacy group were unlikely to be represented in this study, and thus represent selection bias. Furthermore, patients who are members of patient advocacy groups could be more likely to be engaged and to seek out information, so the extent to which the sample is representative of the general population with CID remains unknown, also representing selection bias. As the study data did not capture disease activity, interpretations of how disease severity may have affected patients' FPP concerns cannot be accurately drawn. Additionally, these results are subject to recall bias, as no medical records were reviewed and the survey relied on self-reported data.

\section{CONCLUSIONS}

In conclusion, Danish patients of reproductive age with CIDs have concerns related to their disease which affect decisions throughout the family planning journey. The present study highlights an unmet need for healthcare professionals in Denmark to proactively provide standardised, accessible family planning information in line with international recommendations, as well as in which patient populations these might be most required.

\section{ACKNOWLEDGEMENTS}

The authors thank the participants, the patient advocacy groups (The Arthritis Association [Gigtforeningen], The Association for Spinal Arthritis and Bechterew's Disease [Foreningen for Rygsøjlegigt og Morbus Bechterew] and The Psoriasis Association [Psoriasisforeningen]), the investigators and their teams who took part in this study. Survey implementation and data collection was managed by Incentive Denmark.

Funding. This study and Rapid Service Fee was funded by UCB Pharma.

Medical Writing. The authors also acknowledge Vanessa Omnou, MSc, and Beverley Wilson, PhD, Costello Medical, UK, for medical writing and editorial assistance based on the authors' input and direction. This study was funded by UCB Pharma in accordance with Good Publication Practice (GPP3) guidelines (http://www.ismpp.org/gpp3).

Authorship. All named authors meet the International Committee of Medical Journal Editors (ICMJE) criteria for authorship for this 
article, take responsibility for the integrity of the work as a whole, and have given their approval for this version to be published.

Authorship Contributions. Substantial contributions to study conception and design: Cæcilie B Johansen, Trine B Laurberg, Alexander Egeberg, Ulla-Fie A Jensen, Asbjørn L Hansen, Lone Skov, Lars E Kristensen, Simon F Thomsen and Karen Schreiberf. Substantial contributions to analysis and interpretation of the data: Cæcilie B Johansen, Trine B Laurberg, Alexander Egeberg, Ulla-Fie A Jensen, Asbjørn L Hansen, Lone Skov, Lars E Kristensen, Simon F Thomsen and Karen Schreiberf. Drafting the article or revising it critically for important intellectual content: Cæcilie B Johansen, Trine B Laurberg, Alexander Egeberg, Ulla-Fie A Jensen, Asbjørn L Hansen, Lone Skov, Lars E Kristensen, Simon F Thomsen and Karen Schreiberf. Final approval of the version of the article to be published: Cæcilie B Johansen, Trine B Laurberg, Alexander Egeberg, Ulla-Fie A Jensen, Asbjørn L Hansen, Lone Skov, Lars E Kristensen, Simon F Thomsen and Karen Schreiberf.

Prior Presentation. An abstract summarising data from this manuscript was submitted to, and accepted for poster presentation at the European Alliance of Associations for Rheumatology (EULAR) 2020 Virtual Congress (from 3 June 2020; online): Schreiber K, Johansen C, Jensen UF, et al. PARE0024 Awareness about family planning and pregnancy expectation among patients with chronic inflammatory disease of the skin or joints (Annals of the Rheumatic Diseases 2020;79:1297-1298).

Disclosures. Cæcilie B Johansen: Advisory Boards for UCB Pharma; honoraria as consultant and/or speaker for Galderma, Estee Lauder Companies L'Oréal. Trine B Laurberg: Consultant and/or Advisory Boards for AbbVie and UCB Pharma. Karen Schreiberf: Consultant and/ or Advisory Boards for UCB Pharma. Alexander Egeberg: Research funding from AbbVie, BristolMyers Squibb, the Danish National Psoriasis Foundation, Eli Lilly, Janssen Pharmaceuticals, the Royal Hofbundtmager Aage Bang Foundation, the Simon Spies Foundation, Novartis and
Pfizer; honoraria as consultant and/or speaker from AbbVie, Almirall, Bristol-Myers Squibb, Dermavant, Eli Lilly, Janssen Pharmaceuticals, Galapagos NV, Galderma, LEO Pharma, Mylan, Novartis, Pfizer, Samsung Bioepis Co. Ltd., Sun Pharmaceuticals and UCB Pharma. Ulla-Fie A Jensen: Employee of UCB Pharma. Asbjørn L Hansen: Former employee of UCB Pharma. Lone Skov: Speaker for AbbVie, Sanofi, Eli Lilly, LEO Pharma and Novartis; consultant and/or Advisory Boards for AbbVie, Almirall, Eli Lilly, Janssen Pharmaceuticals, LEO Pharma, Novartis, UCB Pharma, BMS and Sanofi; research and educational grants from AbbVie, Janssen Pharmaceuticals, LEO Pharma, Novartis, BMS and Sanofi. Lars E Kristensen: Consultant and/or Advisory Boards and/or speaker for AbbVie, Amgen, Biogen, Bristol-Myers Squibb, Eli Lilly, Gilead, Janssen Pharmaceuticals, MSD, Novartis, Pfizer, Sanofi and UCB Pharma. Simon F Thomsen: Consultant and/or Advisory Boards for AbbVie, Almirall, Celgene, Eli Lilly, Janssen Pharmaceuticals, LEO Pharma, Novartis, Pfizer, Roche and Sanofi; speaker for AbbVie, Eli Lilly, LEO Pharma, Novartis, Sanofi and UCB Pharma; research support from Abbvie, LEO Pharma, Janssen Pharmaceuticals, Novartis, Sanofi and UCB Pharma.

Compliance with Ethics Guidelines. Ethics approval was not required for this study. Under Danish legislation, questionnaire survey projects not involving human biological material are exempt from the obligation to notify the scientific ethics committee (Section 14 (2) of the Committee Act). Respondents were provided information on the conduct of the survey and had to provide consent before participating. Respondents were informed that the knowledge collected in the survey would be published and had to provide consent before participating.

Data Availability. Data from non-clinical studies is outside of UCB's data-sharing policy.

Open Access. This article is licensed under a Creative Commons Attribution-NonCommercial 4.0 International License, which permits any non-commercial use, sharing, adaptation, distribution and reproduction in any medium 
or format, as long as you give appropriate credit to the original author(s) and the source, provide a link to the Creative Commons licence, and indicate if changes were made. The images or other third party material in this article are included in the article's Creative Commons licence, unless indicated otherwise in a credit line to the material. If material is not included in the article's Creative Commons licence and your intended use is not permitted by statutory regulation or exceeds the permitted use, you will need to obtain permission directly from the copyright holder. To view a copy of this licence, visit http://creativecommons.org/licenses/by$\mathrm{nc} / 4.0 /$.

\section{REFERENCES}

1. Broms G, Kieler H, Ekbom A, et al. Anti-TNF treatment during pregnancy and birth outcomes: a population-based study from Denmark, Finland, and Sweden. Pharmacoepidemiol Drug Saf. 2020;29(3):316-27.

2. Norgaard $\mathrm{M}$, Larsson $\mathrm{H}$, Pedersen $\mathrm{L}$, et al. Rheumatoid arthritis and birth outcomes: a Danish and Swedish nationwide prevalence study. J Intern Med. 2010;268(4):329-37.

3. Bazzani C, Andreoli L, Agosti M, Nalli C, Tincani A. Antirheumatic drugs and reproduction in women and men with chronic arthritis. RMD Open. 2015;1(Suppl 1):e000048.

4. Brouwer J, Hazes JM, Laven JS, Dolhain RJ. Fertility in women with rheumatoid arthritis: influence of disease activity and medication. Ann Rheum Dis. 2015;74(10):1836-41.

5. Cather J, Latremouille-Viau D, Horn E, Bao Y. Psoriasis is significantly associated with lower rates of pregnancy and live births. J Am Acad Dermatol. 2012;66(4):AB200.

6. de Man YA, Hazes JM, van der Heide $H$, et al. Association of higher rheumatoid arthritis disease activity during pregnancy with lower birth weight: results of a national prospective study. Arthritis Rheum. 2009;60(11):3196-206.

7. Jakobsson GL, Stephansson O, Askling J, Jacobsson LT. Pregnancy outcomes in patients with ankylosing spondylitis: a nationwide register study. Ann Rheum Dis. 2016;75(10):1838-42.

8. Jawaheer D, Zhu JL, Nohr EA, Olsen J. Time to pregnancy among women with rheumatoid arthritis. Arthritis Rheum. 2011;63(6):1517-21.

9. Johansen CB, Jimenez-Solem E, Haerskjold A, Sand FL, Thomsen SF. The use and safety of TNF inhibitors during pregnancy in women with psoriasis: a review. Int J Mol Sci. 2018;19(5):1349.

10. Boyd AS, Morris LF, Phillips CM, Menter MA. Psoriasis and pregnancy: hormone and immune system interaction. Int J Dermatol. 1996;35(3):169-72.

11. Gottlieb AB, Ryan C, Murase JE. Clinical considerations for the management of psoriasis in women. Int J Women's Dermatol. 2019;5(3):141-50.

12. Murase JE, Chan KK, Garite TJ, Cooper DM, Weinstein GD. Hormonal effect on psoriasis in pregnancy and post partum. Arch Dermatol. 2005;141(5):601-6.

13. Timur $H$, Tokmak A, Turkmen GG, Ali Inal $H$, Uygur D, Danisman N. Pregnancy outcome in patients with ankylosing spondylitis. J Mater Fetal Neonatal Med. 2016;29(15):2470-4.

14. Berman M, Zisman D, Wollman J, et al. The effect of pregnancy on disease activity in patients with psoriatic arthritis. J Rheumatol. 2018;45(12):1651-5.

15. Ferreira C, Azevedo A, Nogueira M, Torres T. Management of psoriasis in pregnancy-a review of the evidence to date. Drugs Context. 2020;9:1-9.

16. Polachek A, Polachek Shlomi I, Spitzer K, et al. Outcome of pregnancy in women with psoriatic arthritis compared to healthy controls. Clin Rheumatol. 2019;38(3):895-902.

17. Arnone M, Takahashi MDF, Carvalho AVE, et al. Diagnostic and therapeutic guidelines for plaque psoriasis-Brazilian Society of Dermatology. An Bras Dermatol. 2019;94(2 Suppl 1):76-107.

18. Gotestam Skorpen C, Hoeltzenbein M, Tincani A, et al. The EULAR points to consider for use of antirheumatic drugs before pregnancy, and during pregnancy and lactation. Ann Rheum Dis. 2016;75(5):795-810.

19. Andreoli L, Bertsias GK, Agmon-Levin N, et al. EULAR recommendations for women's health and the management of family planning, assisted reproduction, pregnancy and menopause in patients with systemic lupus erythematosus and/or 
antiphospholipid syndrome. Ann Rheum Dis. 2017;76(3):476-85.

20. Flint J, Panchal S, Hurrell A, et al. BSR and BHPR guideline on prescribing drugs in pregnancy and breastfeeding-part I: standard and biologic disease modifying anti-rheumatic drugs and corticosteroids. Rheumatology. 2016;55(9):1693-7.

21. Flint J, Panchal S, Hurrell A, et al. BSR and BHPR guideline on prescribing drugs in pregnancy and breastfeeding-part II: analgesics and other drugs used in rheumatology practice. Rheumatology. 2016;55(9):1698-702.

22. Sammaritano LR, Bermas BL, Chakravarty EE, et al. 2020 American College of Rheumatology guideline for the management of reproductive health in rheumatic and musculoskeletal diseases. Arthritis Care Res. 2020;72(4):461-88.

23. Nast A, Smith C, Spuls PI, et al. Living EuroGuiDerm Guideline for the systemic treatment of psoriasis vulgaris. The European Dermatology Forum (EDF). 2020 https://www.edf.one/home/ Guidelines/EuroGuiDerm-psoriasis-vulgaris.html.

24. Chakravarty E, Clowse ME, Pushparajah DS, Mertens S, Gordon C. Family planning and pregnancy issues for women with systemic inflammatory diseases: patient and physician perspectives. BMJ Open. 2014;4(2):e004081.

25. Lebwohl M, Siegel M, Shankle L, Pisenti L, Yassine M, Van Vorhees S. A comprehensive survey assessing the family planning needs of women with psoriasis. SKIN J Cutan Med. 2018;2:S89.

26. Ackerman IN, Jordan JE, Van Doornum S, Ricardo M, Briggs AM. Understanding the information needs of women with rheumatoid arthritis concerning pregnancy, post-natal care and early parenting: a mixed-methods study. BMC Musculoskelet Disord. 2015;16:194.

27. Vena GA, Cassano N, Bellia G, Colombo D. Psoriasis in pregnancy: challenges and solutions. Psoriasis. 2015;5:83-95.

28. Lindegaard HMVA, Uhrenholt L, Askaa B, et al. Graviditet, amning og mandlig reproduktion ved autoimmune, reumatologiske sygdomme. 2019. https://danskreumatologi.dk/nbv/sygdomme/ graviditet-amning-og-mandlig-reproduktion-vedautoimmune-reumatologiske-sygdomme/.

29. Selskab DD. Retningslinjer for behandling af psoriasis med 2. generations immunomodulatorisk behandling. 2019 [1-10]. https://dds.nu/wpcontent/uploads/2019/12/Guideline-DDS-2.generations-immunomodulatorisk-behandlingfinal-oktober-2019.pdf.
30. Murase J, De Simone C, Fischer-Betz R, Ecoffet C. Fears and misconceptions of women with chronic inflammatory diseases on their journey to motherhood: 8060. J Am Acad Dermatol. 2019;81(4):AB65.

31. Lopez-Medina C, Ramiro S, van der Heijde D, Sieper J, Dougados M, Molto A. Characteristics and burden of disease in patients with radiographic and nonradiographic axial Spondyloarthritis: a comparison by systematic literature review and meta-analysis. RMD Open. 2019;5(2):e001108.

32. Andersen YMF, Wu JJ, Thyssen JP, Egeberg A. Chronologic order of appearance of immune-mediated inflammatory diseases relative to diagnosis of psoriasis. J Am Acad Dermatol. 2019;81(6): 1283-91.

33. Simpson JK, Wilson M, Ahmed AA, Mizara A, Clarke A, McBride SR. An exploratory study using framework analysis to investigate health-seeking behaviour in patients with psoriasis. Br J Dermatol. 2017;177(3):742-50.

34. Birru Talabi M, Clowse MEB, Blalock SJ, Hamm M, Borrero S. Perspectives of adult rheumatologists regarding family planning counseling and care: a qualitative study. Arthritis Care Res. 2020;72(3): 452-8.

35. Birru Talabi M, Clowse MEB, Schwarz EB, Callegari LS, Moreland L, Borrero S. Family planning counseling for women with rheumatic diseases. Arthritis Care Res. 2018;70(2):169-74.

36. Nelson-Piercy C, Vlaev I, Harris K, Fischer-Betz R. What factors could influence physicians' management of women of childbearing age with chronic inflammatory disease? A systematic review of behavioural determinants of clinical inertia. BMC Health Serv Res. 2019;19(1):863.

37. Siddhanamatha HR, Heung E, Lopez-Olivo MLA, et al. Quality assessment of websites providing educational content for patients with rheumatoid arthritis. Semin Arthritis Rheum. 2017;46(6): 715-23.

38. Bylund CL, Gueguen JA, Sabee CM, Imes RS, Li Y, Sanford AA. Provider-patient dialogue about Internet health information: an exploration of strategies to improve the provider-patient relationship. Patient Educ Couns. 2007;66(3):346-52.

39. Smith CJF, Bandoli G, Kavanaugh A, Chambers CD. Birth outcomes and disease activity during pregnancy in a prospective cohort of women with psoriatic arthritis and ankylosing spondylitis. Arthritis Care Res. 2019;72:1029-37. 
40. Phillips R, Pell B, Grant A, et al. Identifying the unmet information and support needs of women with autoimmune rheumatic diseases during pregnancy planning, pregnancy and early parenting: mixed-methods study. BMC Rheumatol. 2018;2:21.
41. Bae YS, Van Voorhees AS, Hsu S, et al. Review of treatment options for psoriasis in pregnant or lactating women: from the Medical Board of the National Psoriasis Foundation. J Am Acad Dermatol. 2012;67(3):459-77. 